\title{
Tecnologias de comunicação em centrais de relacionamento: autonomia sob a égide do controle
}

Communication technologies in relationship centers: autonomy under the shelter of control

Tecnologías de la comunicación en centrales de relación: autonomía bajo la égida del control

Valéria de Fátima Raimundo

- Doutora em Sociologia e mestre em Comunicação e Sociabilidade Contemporânea pela Universidade Federal de Minas Gerais (UFMG)

- Especialista em Jornalismo pela Faculdade de Filosofia Ciências e Letras de Belo Horizonte

- Graduada em Relações Públicas pelo Instituto Cultural Newton Paiva

- Coordenou o Curso de Relações Públicas do Centro Universitário Belo Horizonte, onde implantou o Curso de Pós-Graduação em Comunicação Empresarial

- É professora do Curso de Comunicação da UFMG

- Desenvolve pesquisas sobre comunicação organizacional e processo de trabalho

-vraymundo@gmail.com 
Resumo

A convergência entre telecomunicações e computação maximizou a importância dessas centrais como instrumentos de interação entre as organizações e os seus stakeholders. As facilidades tecnológicas permitiram um melhor dimensionamento dessas centrais, entre as quais se destacam as ouvidorias. Uma das consequências disso foi o impacto, na maioria das vezes, positivo na prestação de melhores serviços aos consumidores. Por outro lado, no que concerne aos teleatendentes, a lógica da organização do trabalho quase sempre rígida, cheia de regras e sob intenso controle, é paradoxal diante da necessidade do exercício da autonomia.

PALAVRAS-CHAVE: CENTRAL dE RELACIONAMENTO • TECNOLOGIA DE COMUNICAÇÃO • CONTROLE • AUTONOMIA

\section{Abstract}

The convergence between telecommunications and computer science has maximized the importance of CRCs as instruments for interaction between organizations and their stakeholders. Technological resources have enabled better sizing of these centers, among which one highlights the listener's office services. One main positive consequence is the quality of the customer services being offered. On the other hand, as regards call attendants perspective, the logic of organization of a very restricted job routine - one that is full of norms and under intense control - is paradoxical with the need of exercising autonomy.

KEYWORDS: COSTUMER RELATIONSHIP CENTER • COMMUNICATION TECHNOLOGY • CONTROL • AUTONOMY

Resumen

La convergencia entre las telecomunicaciones y la informática elevó al máximo la importancia de estas centrales como medios de interacción entre estas organizaciones y sus stakeholders. Los avances tecnológicos han permitido un mejor diseño de estas centrales, entre las cuales se destacan las defensorías. Una de las consecuencias fue el impacto, en la mayoría de los casos positivo, en la prestación de mejores servicios a los consumidores. Por otra parte, en lo que concierne a los profesionales de teleatención, la lógica de la organización del trabajo suele ser rígida, llena de reglas y sometida a un control intenso, lo que resulta paradójico ante la necesidad del ejercicio de la autonomía.

PALABRAS CLAVE: CENTRAL DE SERVICIO AL CLIENTE • TECNOLOGÍA DE LA COMUNICACIÓN • CONTROL • AUTONOMÍA 
A complexidade da sociedade contemporânea tem suscitado debates de várias áreas do conhecimento e, consequentemente, apresentado como resultado uma diversidade de interpretações com abordagens pluridisciplinares sobre esse tema. O campo da comunicação, nessa discussão, é visto não só como locus de convergência de diversas matrizes disciplinares, mas também como uma referência na busca de orientações epistemológicas e metodológicas em pesquisas, cujo objeto atravessa, hibridiza ou tem interface com esse campo de alguma maneira. Nessa perspectiva, tem-se a comunicação organizacional como um tema recorrente das pesquisas em comunicação. Segundo Deetz (1997), Jameson (1997) e Lyotard (1997), comunicação - especialmente na sua interface tecnológica -, organizações empresariais e mudanças são os elementos centrais constitutivos e caracterizadores da contemporaneidade. Participação, flexibilidade, diálogo, autonomia são algumas das palavras que marcam os relacionamentos de trabalho nas empresas imersas na lógica atual de desenvolvimento, instaurada na competitividade acirrada no mercado global.

Nesse contexto, a comunicação organizacional surge como um tema crescente de interesse. Decorrente disso, foram desenvolvidos estudos a partir de vários enfoques (PUTNAM , PHILIPS e CHAPMAN, 1996; DEETZ, 1995; KUNSCH, 1997; REIS e COSTA, 2007), que, podemos dizer, apresentam contribuições importantes não só para a área, mas também para uma melhor compreensão do que seja a especificidade que caracteriza a contemporaneidade. Apesar disso, podemos perceber, na literatura, um gap em termos de estudos e produção científicos relacionados à busca de uma melhor compreensão de como a comunicação, na contemporaneidade, influencia o contexto de trabalho das organizações. Este estudo pretende ser uma contribuição para o preenchimento desse gap.

Este artigo apresenta alguns resultados da pesquisa de campo que realizei para minha tese de doutoramento em Sociologia, Comunicação organizacional no trabalho mediado pelas novas mídias: estudo analítico das percepções de lideranças $e$ teleatendentes em centrais de relacionamento (RAIMUNDO, 2009). A pesquisa levantou e avaliou a comunicação nas centrais de relacionamento de duas organizações, uma pública e outra privada, em um contexto de interdisciplinaridade entre os campos da comunicação e da sociologia do trabalho.

A pergunta norteadora da pesquisa foi sobre como a mediação do processo de trabalho feita pelas novas mídias influencia os padrões interativo-comunicacionais nas organizações, sobretudo daquelas que se intitulam flexibilizadas no seu processo de gestão pelo uso de tecnologias de comunicação.

Trata-se de uma análise comparativa sobre a forma como os trabalhadores das centrais de relacionamento, tendo como lugares de fala as suas posições na hierarquia, representam, classificam e organizam as experiências referentes às categorias que articulam as interações comunicacionais nessas equipes de trabalho. O ponto de partida é o reconhecimento da centralidade das novas tecnologias de comunicação, aqui entendidas como novas mídias na confor- 
mação das interações comunicacionais. Ele está ancorado nas discussões de autores que, a partir de enfoques distintos, comungam desse pensamento (BARBERO, 2001; BRAGA, 2001; DEETZ, 1997; FAUSTO NETO, 2007; SODRÉ, 2008; THOMPSON, 2008). No encalço das discussões apresentadas por esses autores buscamos compreender os meandros do elo entre o sistema técnico e a constituição de espaços de conversação e voz no âmbito dessas centrais.

O pressuposto é que, vistas da perspectiva interacional, as novas mídias funcionam como mediadoras do trabalho e dão conformação de dialogicidade aos padrões interativo-comunicacionais existentes no processo de tomada de decisões dessas equipes. Outro pressuposto é que o diálogo e a flexibilidade característicos das interações comunicacionais midiatizadas, nesse contexto, tendem a imprimir mais autonomia aos trabalhadores das equipes na resolução de questões relativas às suas rotinas de trabalho ${ }^{1}$. Consideramos que a articulação do trabalho dessas equipes se constitui de uma dimensão interacional nos seus processos comunicativos, que é peculiar aos grupos de trabalhadores, os quais, nesse caso, são distintos. Nessa perspectiva, as equipes, por sua vez, funcionam como loci de convergência de interações comunicacionais concernentes à natureza do seu processo de trabalho.

Para fins deste artigo, abordaremos a organização de economia mista (capital privado e estatal), doravante nomeada Alfa, que usa o termo call center para designar seu setor de atendimento a clientes. Apesar de ser o centro de reclamações e solicitações dos clientes da empresa, a central de relacionamento não é constituída como uma ouvidoria, o que não impede que os procedimentos no exercício das funções dos seus teleatendentes sejam semelhantes aos dos teleatendentes de uma ouvidoria. Em ambos os casos, cabem a eles a triagem das reclamações e o atendimento telefônico. Em suas rotinas de trabalho, eles abrem os processos, encaminham os questionamentos e fazem contatos necessários com os clientes.

A central de relacionamento da Alfa foi escolhida como unidade de análise deste estudo porque, além de fazer parte de um setor que tem demonstrado expressivo crescimento nos últimos anos, em termos de faturamento e de geração de postos de trabalho, ela tem como prerrogativa a divisão do trabalho em equipes. Os trabalhadores usam, no exercício das suas funções, tecnologias de comunicação que vão das mais remotas às mais sofisticadas,. Além disso, o setor é pautado pelos mesmos princípios que orientam a concepção de organizações flexíveis, tais como autonomia para tomar decisões, participação, flexibilidade e diálogo. Isso, apesar de seu funcionamento, paradoxalmente e aparentemente, apresentar características que sugerem uma maior aproximação com o modelo de uma organização industrial.

10 aporte teórico para a análise dos dados centra-se nas discussões sobre o paradigma interacional, travadas nas esferas comunicacional e sociológica. Por interações comunicacionais entendemos as trocas comunicacionais entre os integrantes dessas equipes, no exercício cotidiano das suas funções. 


\section{ESPECIFICANDO AS CATEGORIAS DE ANÁLISE}

A grounded theory ${ }^{2}$ foi o método de análise de dados utilizado em nosso estudo. Trata-se de uma abordagem que propicia a compreensão das situações investigadas a partir do contexto do qual emergem os sentidos atribuídos pelos sujeitos participantes da pesquisa.

O modelo de análise que propomos foi apresentado aos sujeitos participantes da pesquisa a partir das categorias que o constituem. Considerou-se o modo como eles representam, classificam e organizam as experiências no âmbito de cada uma delas. O imbricamento dos suportes tecnológicos com as interações não foi abordado na perspectiva do aparato em si, tampouco a partir dele. Antes, o nosso propósito foi identificar e analisar as percepções dos entrevistados sobre as categorias iniciais, por entendermos que esta seria uma conduta consonante com a grounded theory, segundo a qual a teoria surge do contexto das análises e não o contrário.

Em nossa tese, a observação de campo foi utilizada com o objetivo de descrever e caracterizar a constituição dos espaços midiatizados de expressão e voz entre as equipes da central de relacionamento da Alfa e as dimensões decisórias na esfera da organização interna ao grupo. Foram constituídos grupos de discussão de natureza fenomenológica, com a participação de doze pessoas, com idade, gênero e tempos de trabalho diferentes na organização investigada.

As categorias iniciais de análise escolhidas como necessárias à abordagem do objeto da pesquisa foram novas mídias, diálogo, flexibilidade, participação e autonomia. As reflexões realizadas sobre o seu imbricamento nos conduzem à proposta de um modelo de relações entre elas, representado a seguir (Figura 1), o qual tomamos como ponto de partida no processo de análise dos dados.

Essa proposta sugere que a natureza dialógica das interações comunicacionais é construída pelos sujeitos participantes do processo comunicacional. O diálogo é instituinte da ação comunicativa e, como tal, favorece a construção de um sentido de autonomia que se manifesta com a participação efetiva dos sujeitos no processo de tomada de decisão. As novas mídias funcionam como fomentadoras das interações comunicacionais e da flexibilidade necessárias ao processo.

A interação comunicacional como uma referência conceitual para a análise de processos comunicacionais é central nesse trabalho. Tomamos como ponto de partida as importantes contribuições de Braga (2001, p. 17-18). Para o autor, "a interação comunicacional é constituída de processos simbólicos e práticos

2 A grouded theory é definida por Glaser e Strauss (1967) como uma teoria de natureza indutiva, que se conforma a partir do estudo dos fenômenos aos quais está imbricada. Nesse caso, ao invés de uma sobreposição dos conceitos teóricos aos dados, tem-se que a teoria emerge das análises desses mesmos dados (YUNES; SZYMANSKI, 2005). 
Figura 1 - Modelo de relações entre as categorias de análise

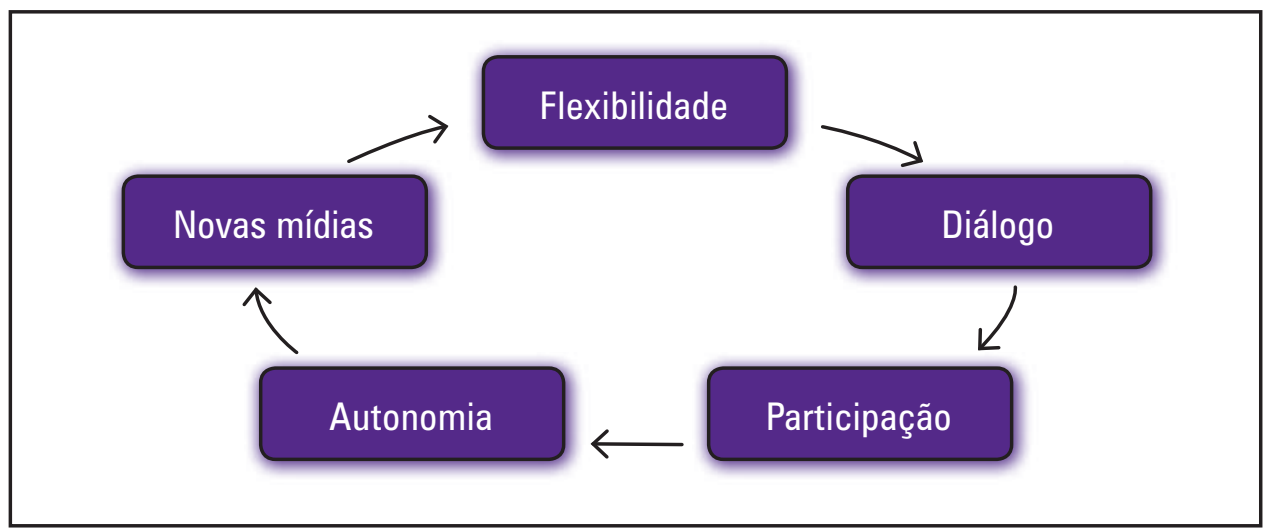

Fonte: A autora

que, organizando trocas entre os seres humanos, viabilizam as diversas ações e os objetivos em que se veem engajados”. Ele acrescenta que toda atuação explicita um ato de coparticipação. Na esfera da comunicação, a interação, vista nessa perspectiva, ou seja, como a realização de trocas entre os interlocutores, desloca o foco da relação linear - portanto, redutora - entre emissores e receptores para uma abordagem relacional, na qual os interlocutores assumem o lugar de sujeitos, (des)construindo sentidos.

No âmbito da sociologia, destacamos a abordagem da interação apresentada por Simmel (2006, p.60) como sociação ${ }^{3}$, ou seja, uma "forma na qual os indivíduos se desenvolvem conjuntamente em direção a uma unidade no seio da qual esses interesses se realizam”.

É necessário destacarmos a ressalva de Simmel (2006, p. 60) de que, entre outras formas de agregação dos indivíduos, o trabalho, em si e por si, não revela aspectos genuínos de interações. Antes, é elemento de sociações quando destituído do caráter de uma agregação isolada dos indivíduos, para, em seu lugar, ser uma forma de "estar com o outro e de ser para o outro".

\section{Autonomia}

Autonomia foi uma categoria bastante citada pelos entrevistados e muitas vezes associada à categoria flexibilidade.Vejamos o depoimento a seguir:

3 Simmel define como conteúdo e matéria da sociação: “Tudo o que está presente neste de modo a engendrar ou mediatizar os efeitos sobre os outros, ou receber esses efeitos dos outros. Tudo o que existe nos indivíduos e nos lugares concretos de toda realidade histórica como impulso, interesse, finalidade, tendências, condicionamento psíquico e movimento nos indivíduos." (SIMMEL, 2006, p. 60). 
Às vezes tem muitas questões de erro no sistema, às vezes erro de pessoas. Então, a gente tem que ter assim uma autonomia maior. E a gente tem certa flexibilidade, porque, às vezes, o cliente tem um laudo lá que comprova que eu posso fazer tal pedido pra ele. Ótimo, o laudo foi recusado na agência, pela pessoa da agência. Eu posso pedir ao cliente que ele me envie um fax ou e-mail. ${ }^{4}$

A relação estabelecida pelo entrevistado entre as duas categorias é circunscrita à dimensão operacional do exercício da sua função. Aqui ele demonstra que é possível rever o percurso de um procedimento equivocado no atendimento ao cliente e corrigir a situação, de modo a evitar que a falha identificada por ele seja revertida, negativamente, para a organização.

Na percepção da maioria dos entrevistados, exercer a autonomia significa, em certa medida, romper com a lógica prescritivo-normativa, característica da organização do processo de trabalho da central de relacionamento. É quebrar regras. Nessa perspectiva, a autonomia é sintetizada pelo teleatendente na descrição da sua habilidade e desenvoltura para lidar com situações que fogem ao script.

Outros entrevistados foram mais cautelosos em relação ao exercício da autonomia. No depoimento a seguir, um dos informantes também admitiu que é possível "fugir à regra". Nesse caso, ao mencionar o sistema, ele fez referência ao procedimento operacional padrão (POP), que é disponibilizado para consulta obrigatória no computador de cada teleatendente.

A autonomia que nós temos nada mais é do que fugir à regra. Em alguns casos a gente pode fugir da regra, mas em outros não. Nem tem acesso, acesso no sistema mesmo, fisicamente falando, pra quebrar essas regras. Alguma coisa a gente pode fazer, como ligar pra área técnica. Pra essas coisas a gente tem essa certa autonomia.

No depoimento seguinte, o entrevistado descreve como exerceu a autonomia em uma situação considerada emergencial, afirmando ter contornado a rigidez do sistema operacional:

Já aconteceu comigo um caso de uma cliente que não tinha a religação de urgência pra cidade dela. A pessoa entrou em contato comigo, era um caso de saúde. O que eu fiz? Só podia cadastrar um pedido de quarenta e oito horas, porque o sistema barrava situação de urgência. Eu cadastrei o procedimento de quarenta e oito horas, liguei na região e pedi pra eles atenderem o mais rápido possivel.

Outra relação da autonomia estabelecida pelo teleatendente no exercício da sua função é a de poder fazer contato com os clientes e buscar apoio em outros setores, quando a situação exige: "No nosso setor, nós temos autonomia de ligar pra clientes, ligar pra setores".

4 Os depoimentos são transcritos mantendo-se o mais possível o original. 
Alguns depoimentos ratificaram a percepção da autonomia na forma descrita acima, mas deixaram explícito que a consideram relativa ("Eu tenho até certo ponto, eu tenho autonomia de buscar informação") e sugeriram que o aspecto qualitativo da autonomia está relacionado com as características dos serviços que são prestados aos clientes pela central de relacionamento. O tipo de serviço demanda uma forma específica de interação do teleatendente com o cliente.

Outros entrevistados foram mais categóricos ao afirmarem a inexistência de autonomia. As iniciativas que tomam em relação ao trabalho não se configuram como exercício da autonomia. Antes, para eles suas atitudes se restringem ao "grosso, o básico", ao cumprimento da função.

No caso do hotline a gente não tem autonomia, não tem, você não pode fazer nada. Tudo que você vai fazer, se você vai fazer alguma coisa tem que ver com o supervisor pra que ele possa estar encaminhando. É isso que a gente faz é fazer o grosso, o básico mesmo.

A única autonomia que a gente tem, que não é uma autonomia, caso assim o cliente liga reclamando, é gerar um contato pra cadastrar pra eles apurarem se aconteceu mesmo e estarem orientando o atendente a fazer o procedimento correto.

\section{Diálogo}

O diálogo surge como subcategoria relacionada à troca de informações entre os membros da equipe e também com os de outros setores. Aqui ele também é visto como um instrumento, por meio do qual são assegurados os procedimentos necessários ao cumprimento das tarefas ("Ele serve até pra você identificar o que o cliente deseja"). Como instrumento de troca de informações, ele tem "seus prós e seus contras", como relatou um dos entrevistados:

O diálogo, no meu setor ele se faz muito importante porque às vezes a gente pega um caso que você necessita de outros setores da empresa, da mesma equipe pra poder solucionar um problema. Então, o diálogo tem seus prós e tem seus contras. As pessoas dialogando quando você está no atendimento pode às vezes atrapalhar.

Outro integrante do grupo de discussão também tem essa percepção do diálogo. No seu caso, ele chega a ser "inevitável" para a realização do atendimento ao cliente e também para o acesso aos supervisores, na obtenção de informações e esclarecimento de dúvidas.

Outro entrevistado considerou o diálogo uma "ferramenta de trabalho primordial". A voz é, para ele, o meio de comunicação com o qual transmite segurança no atendimento ao cliente e também adquire confiança entre seus pares, para resolver questões relacionadas à execução das suas tarefas. Para o informante, o entendimento é essencial nas interações comunicacionais entre cliente e colegas da equipe, já que o oposto disso pode "levar em risco a vida das pessoas". 
Por conta desses aspectos, o diálogo, para ele, "vai muito além de um instrumento de conversa": "O diálogo pra gente é uma ferramenta, é um guia de informação".

Para a maioria dos teleatendentes, a interação com o cliente é viabilizada por meio do diálogo e isso vale para vários perfis de clientes. É por meio dele que, por exemplo, pessoas "humildes" e "simples" conseguem expressar as suas necessidades de atendimento.

O diálogo também surge associado ao controle e, em um depoimento dado, adotá-lo nas interações comunicacionais com o cliente é uma forma de evitar que um determinado teleatendente "jogue conversa fora", enquanto outros se apressam para não deixar os demais clientes aguardando atendimento. Nesse caso, para o informante, a monitoria deve ser "mais rigorosa".

Um dos entrevistados apresentou uma posição mais crítica sobre a prática do diálogo. Por exemplo, diante de situações de conflito que poderiam surgir em virtude da manifestação contrária a uma conduta adotada no atendimento ao cliente. Ele se mostra incomodado quando, para evitar um conflito interno, se sente obrigado a dizer ao cliente algo que ele não acha correto ("Este é um problema do diálogo"):

Agora, outra coisa que eu queria colocar sobre o diálogo é a questão do conflito que a gente tem sobre qual é o procedimento, o que a gente tem que falar com o cliente. Hoje mesmo eu estava discutindo com o meu supervisor sobre um problema que tivemos; sobre terem trocado a titularidade da conta sem consultar o cliente. Tá seguindo o procedimento? Tá. Pode ser feito? Pode. Achar incorreto eu acho, mas se eu tiver aquele conflito interno...

\section{Participação}

Curiosamente, a participação, que também representava uma categoria inicial de análise, não foi desenvolvida pelo grupo, apesar do nosso esforço. O que podemos inferir, a partir da observação que fizemos sobre essa atitude dos informantes envolvidos na discussão, é que ficou implícita a ideia de que o tema não atravessa o cotidiano de trabalho deles o suficiente para ocupá-los com essa reflexão. Questionados diretamente sobre sua participação nas reuniões realizadas para a definição das metas de produção apenas, um deles se manifestou verbalmente: "não".

\section{Flexibilidade}

A abordagem sobre a flexibilidade feita pelo grupo também não se desvinculou da esfera de interação com o cliente. Como vemos no depoimento a seguir, para alguns ela é necessária para estabelecer "harmonia" na relação com o cliente e a central de relacionamento e dá condições para fazer um trabalho "bem feito": 
Flexibilidade é também você conversar com o cliente, ter uma harmonia entre você e ele, através do telefone, claro. Tentar gerar esse contexto de fazer um pedido bem feito.

Não podemos deixar de considerar a relação que os informantes fazem entre a flexibilidade e o controle. Alguns deles consideraram o processo de trabalho na central de relacionamento pesquisada mais flexível, se comparado com o da terceirizada, e citou como exemplo a liberdade para falar com o cliente, isenta do rigor do monitoramento que, a seu ver, transforma em tortura a obediência ao tempo de médio de atendimento (TMA):

A posição de atendimento (PA) é muito cobrada na terceirizada, tempo de atendimento e monitoria. Aqui já tem uma flexibilidade bem maior, você pode conversar com o cliente e o TMA não vai torturar você.

Para outros a flexibilidade esbarra na existência de normas a serem obedecidas: "A flexibilidade, de certa forma, você passa a ter que segurar até certo ponto, porque você tem normas dentro da empresa". Outros foram mais contundentes e negaram a sua existência:

Na verdade, eu acho que flexibilidade não tem nenhuma, porque, se o cliente liga com alguma coisa pendente, ou não tem nada pendente, você gera ou não gera o pedido dele.

Neste estudo, propositadamente, o controle não foi uma categoria inicial de análise. Durante a realização do levantamento bibliográfico, verificamos que esse tema tem demarcado, expressivamente, as diversas abordagens de pesquisadores sobre o processo de trabalho em centrais de relacionamentos. Não adotá-lo aqui como uma das categorias iniciais de análise foi uma opção, porque pretendíamos explorar as possibilidades metodológicas da grounded theory e verificar se o controle seria apresentado à discussão e de que forma pelos trabalhadores da central de relacionamento investigada. Essa iniciativa resultou na sua evidência como uma importante referência tanto nos depoimentos dos teleatendentes, quanto nos depoimentos dos líderes de equipes, e se tornou uma das principais categorias a ser desenvolvida, com base nas falas dos informantes.

Uma das relações estabelecidas pelos teleatendentes foi do controle com a produtividade. A forma comum de controle da produtividade desses trabalhadores é monitorar os atendimentos que eles fazem aos clientes para garantir que as metas estabelecidas para a duração do tempo médio de atendimento (TMA) sejam cumpridas.

Eu acho que eles, eles proíbem muito as pessoas de estar sendo informal. Cobram tanto a robotização, pelo fato do TMA, porque as pessoas, às vezes, vai conversando e o TMA, subindo.

$\mathrm{Na}$ visão da maioria dos teleatendentes, a rigidez da cobrança impacta negativamente o relacionamento do cliente com a organização. A interação 
comunicacional, nesse caso, foi qualificada por alguns deles como sendo "robotizada". Embora o controle excessivo tenha sido denunciado por alguns integrantes do grupo de discussão, para outros, ele foi visto como necessário à fluidez do processo de trabalho. Alguns chegaram até a discordar da existência de rigor na cobrança do TMA e de uma relação "robotizada" no atendimento ao cliente:

Aqui a gente é cobrado assim: a gente tem que fazer o serviço com agilidade pra atender o máximo que a gente puder. Mas, se o cliente for conversar com você, como a gente aqui não tem robotização, a gente não pode também simplesmente ignorar o cliente, já que eles dão a liberdade.

Curiosamente, a maioria dos teleatendentes contestou a existência do rigor no controle do processo de trabalho. Como muitos deles têm experiências nessa função em outras centrais de relacionamento, eles se remeteram a elas para contrapô-las à sua experiência na central de relacionamento atual. É necessário lembrarmos que muitos são egressos de centrais de relacionamento dotadas de um contingente bem maior de teleatendentes, algumas delas com mais de mil trabalhadores. A equipe à qual eles estavam integrados, à época da pesquisa, era constituída de aproximadamente 170 pessoas. Não é impossível que esse fato influencie esta sua opinião:

Nós temos, mas não é tão cobrado quanto em outros lugares que eu já trabalhei, não é tão cobrado. Tem, mas, é lógico, a gente tem que estar atendendo o cliente dentro de um determinado tempo, porque, senão, a pessoa pode ficar fazendo hora.

O controle, realizado por meio do monitoramento da conduta dos teleatendentes, chegou a ser visto com bons olhos por alguns. Segundo eles, a prática, por vezes, pode ser revertida em seu benefício, sobretudo quando é necessário se defender de alguma acusação que eles consideram indevida, feita pelo cliente. Nesse caso, o controle é uma "faca de dois gumes":

É bom não só por isso, mas é bom também que pessoas que agem de má-fé demais ligam e agem de má-fé. Essa monitoria te resguarda também. As vezes o cliente fala que você não ofereceu tal tipo de serviço, que você não deu informação, simplesmente você pega a gravação e vê se você fez aquilo ali, é um meio de defesa nosso também. É uma faca de dois gumes.

O controle também foi apresentado pelos teleatendentes como um instrumento de punição e seu uso como tal está vinculado ao perfil da liderança à qual eles respondem diretamente. Isso ficou explicitado na fala de um dos informantes:

O supervisor vai te dar um (advertência) porque você chegou atrasado ou atendeu mal o cliente. O cara era um carrasco. 


\section{A CATEGORIA NOVAS MÍDIAS DIANTE DAS DEMAIS CATEGORIAS E SUBCATEGORIAS}

Para fazermos a correlação entre a categoria inicial de análise novas mídias e as demais categorias e as subcategorias que surgiram em decorrência da análise das falas dos teleatendentes, adotamos o mesmo procedimento ao discutirmos essa relação no grupo de líderes. Tomamos como referência, o modelo inicial e chegamos à seguinte reconfiguração:

Figura 2 - Reconfiguração de modelo da correlação entre "novas mídias" e as demais categorias

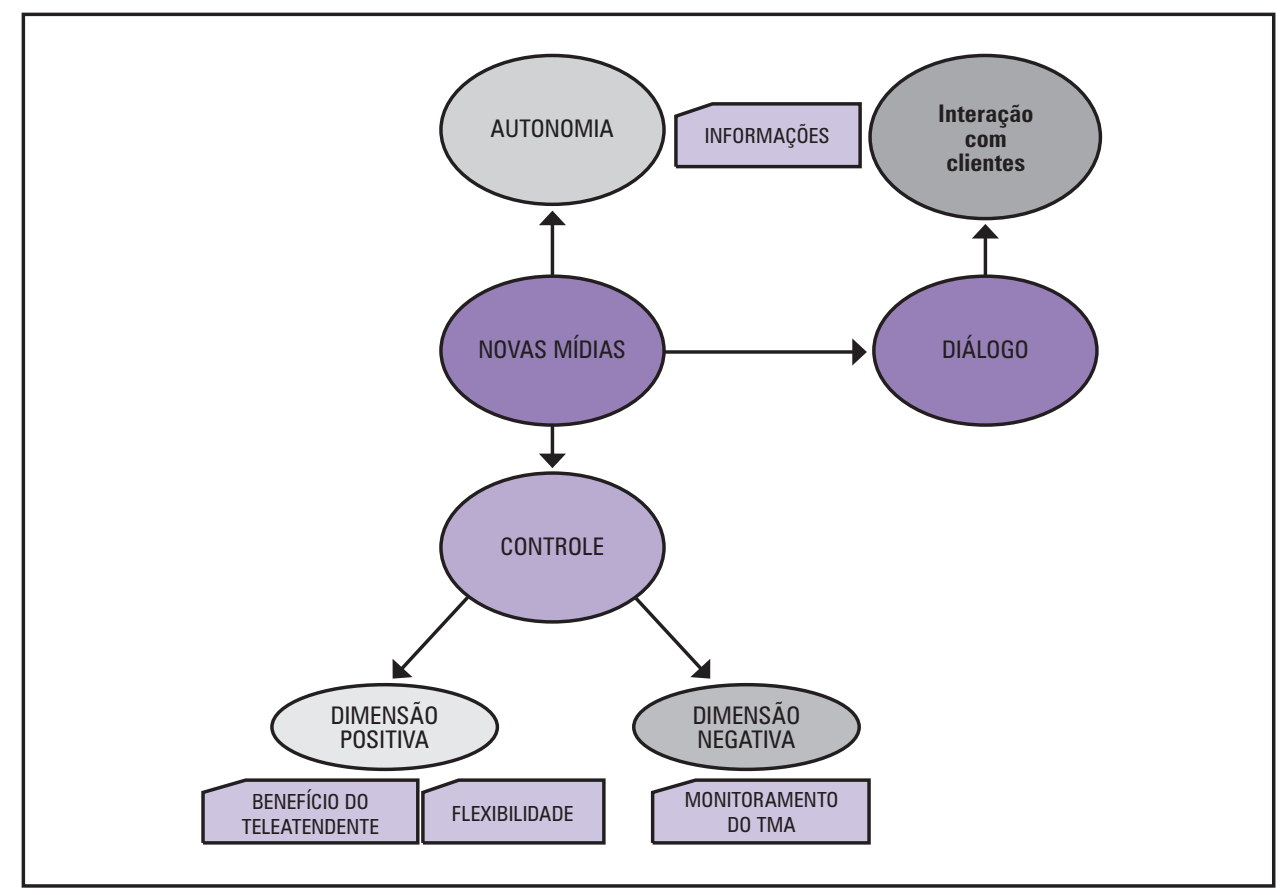

Fonte: A autora

Nesse modelo, a categoria inicial novas mídias é confirmada como principal articuladora das correlações identificadas, em torno da qual as demais categorias e subcategorias se vinculam.

A autonomia foi uma das categorias iniciais que se mantiveram como constituintes do modelo apresentado. Nessa configuração, ela está diretamente vinculada à categoria central, novas mídias, e também à subcategoria interação na equipe. Embora, como vimos em alguns depoimentos, os teleatendentes tenham classificado a autonomia como sendo limitada ou mesmo inexistente, ainda assim ela 
prevaleceu, na visão da maioria deles, como uma ação que se concretiza em suas iniciativas para buscar informações da chefia imediata ou mesmo em outros setores. Suportes como telefone e e-mail são instrumentos utilizados por eles:

Quando a gente precisa fazer alguma coisa, a gente tem que ligar pro supervisor, pra procurar supervisor, e a gente lá já tem um contato mais direto, por e-mail, você liga pro setor responsável.

Eu vou direto no setor, via e-mail, telefone.

Nós temos autonomia de ligar, de mandar e-mail, de acompanhar o caso. Às vezes é simplesmente abrir a ordem e deixar morrer. Nós não temos como interferir nesse tramite, não.

Nos depoimentos a seguir, podemos ver que esses não são os únicos recursos dos quais os teleatendentes lançam mão para concretizar os objetivos da ação:

E-mail, telefone, sinal de fumaça (risos).

Às vezes o cliente ta falando e você não pode falar, que você tá precisando de ajuda do seu supervisor, você levanta a mão.

O diálogo é concebido pelo grupo como "essencial" para gerar entendimento entre o teleatendente e o cliente. No modelo apresentado como categoria inicial de análise, deixa-se de ter um vínculo direto com as novas mídias e se ganha esta posição com as subcategorias interação na equipe e interação com o cliente. Para a maioria dos informantes, por meio do diálogo, é possível articular os processos comunicacionais nessas duas esferas. Na interação na equipe, ele é o instrumento por meio do qual será possível ter acesso às informações necessárias à execução da tarefa; já na interação com o cliente ele é fomentador do entendimento entre os interlocutores nesse processo comunicacional. Nesse novo desenho, as novas mídias têm relação direta com a subcategoria interação com o cliente. Elas são instrumentos necessários à concretização das relações comunicacionais. O depoimento de um dos integrantes do grupo no disse o seguinte sobre isso:

Aqui na $x x x$ nós temos computador, e-mail, fax, sei lá, tudo o que você imaginar. Até webcam tem, até videoconferência, tem tudo. Agora o seu Zé que é lá do sitio Barradão, num córrego grande depois da esquina de Brumadinho, interiorzinho, pequenininho, que nem celular pega direto, o que é que ele tem, um celular talvez, um telefone comunitário? Então o telefone é muito importante.

A exemplo do resultado das correlações feitas entre as categorias iniciais e as subcategorias no grupo de líderes, também aqui o controle surgiu como uma 
subcategoria diretamente vinculada à de novas mídias. De maneira emblemática, ela se desdobra em duas dimensões: a 1, como positiva e a 2, como negativa, com a ressalva de que, aqui, não existe uma sobreposição de importância de uma sobre a outra.

O que consideramos emblemático é o fato de os teleatendentes avaliarem positivamente o uso dos suportes tecnológicos como instrumentos de controle da sua performance no desempenho das funções ("eu acho tranquilo, porque toda empresa tem que manter um controle. Ela tem que saber se o procedimento está sendo feito de forma correta. Como é que ela vai fazer isso sem monitorar o funcionário?)". O monitoramento feito pelos líderes com a audição das gravações dos atendimentos é uma prática considerada legítima pelos teleatendentes e pode funcionar também como uma importante aliada no caso de necessitarem se defender diante de uma atitude considerada por eles como sendo de "má-fé do cliente". Outra maneira de avaliar positivamente o controle que lhes é impingido está relacionada ao uso dos recursos destinados a esta finalidade na realização das tarefas.

Às vezes essa política de controle facilita muito o nosso trabalho. Você vai pegar um caso que outra pessoa já tratou, vê o protocolo, vê o que ela fez certo. Às vezes, você até escuta a gravação pra saber.

Nesse mesmo raciocínio, as práticas de controle podem levá-los a ocupar uma melhor posição, dentro da central de relacionamento, desde que a comprovem por meio de alta performance produtiva:

A gente trabalha com números. Se você oferecer os melhores números possiveis pra empresa, propicia uma a possibilidade de promoção, algo melhor realmente. Então, com certeza, se você é monitorado e tira notas boas na monitoria, não estoura falta, com certeza vocêé mais observado.

A satisfação do cliente também é aferida e usada como instrumento de avaliação do desempenho do teleatendente. O seu resultado pode levar a elogios passíveis de serem divulgados internamente:

Pesquisa de satisfação com o cliente, que o pessoal lá do quinto andar faz. Eles pegam o atendimento sorteado e ligam pra pessoa que conversou com você e fala: ó, eu preciso que você responda cinco perguntas sobre o atendimento de tal pessoa.

As falas desse grupo foram muito marcadas por referências feitas pelos seus integrantes sobre a interação com os clientes. Em decorrência disso e considerando o contexto do qual emergiram as suas expressões, esta se tornou uma subcategoria importante na constituição do modelo. No elenco de justificativas para a legitimação dos mecanismos de controle que incidem sobre eles, está a fiscalização feita por agências nacionais reguladoras que exigem o cumprimento das regras e definem padrões de atendimento aos clientes. Para um dos informantes, o controle, que, nesse caso, é impresso a toda equipe da 
central de relacionamento, é pertinente e está associado ao direito que o cliente tem de ter acesso aos procedimentos protocolares adotados pelo teleatendente responsável pelo seu atendimento. "Nós somos uma empresa de prestação de serviço e temos metas a cumprir. Esse protocolo é exigido, tem que ser fornecido, o cliente tem direito a isso, é obrigado.").

A dimensão 2, como já dissemos, é a negativa, que se desdobra em duas esferas: a da punição e a da rigidez no controle do tempo médio de atendimento (TMA). No caso da punição, ela está diretamente relacionada com o uso dos recursos de controle para justificar as punições aplicadas aos teleatendentes pelos líderes nos caso em que eles infringem alguma norma que rege a sua conduta no exercício da sua função. Os depoimentos que destacamos anteriormente também apresentam uma associação do uso desses recursos ao perfil de algumas lideranças. Alguns deles denunciam o uso desses mecanismos para realizar perseguições de trabalhadores que, por algum motivo, não gozam de boa reputação junto à chefia.

$\mathrm{Na}$ esfera da rigidez do controle do TMA, percebemos uma associação com a subcategoria interação com o cliente, uma vez que, na avaliação da maioria dos informantes, essa rigidez sobre o controle do tempo de duração do atendimento ao cliente impacta negativamente o processo comunicacional entre os interlocutores.

A flexibilidade, também uma categoria inicial, nesse novo desenho se desvincula de uma relação direta com a categoria novas mídias. Ela não chega a desaparecer do modelo, mas ganha outro status ao ser vinculada indiretamente à subcategoria controle por meio da esfera da dimensão positiva. A explicação para isso está no modo como os informantes abordaram essa questão. Eles não estabeleceram vínculos com as novas mídias, mas, sim sob a ótica do controle, avaliaram que, de maneira geral, o processo de trabalho na central de relacionamento investigada é menos vulnerável ao rigor do controle, sobretudo quando comparado com o da terceirizada e o de outras prestadoras desse tipo de serviço, nas quais o número de teleatendentes é quase sempre acima de mil. É necessário observarmos que a maioria dos informantes se valeu de experiências anteriores em centrais de relacionamento desse porte.

Ainda no âmbito dessa discussão a categoria inicial participação é destituída da constituição desse modelo. Neste caso nos valemos das reflexões de Deetz (1997), bem como dos demais autores aqui destacados, de que as novas mídias, de fato, ocupam lugar central na sociedade. Elas influenciam a natureza das interações comunicacionais contemporâneas de maneira expressiva e impactam a sociedade nos moldes como os meios de comunicação de massa tradicionais impactaram, por ocasião do seu surgimento e desenvolvimento.

Em uma perspectiva mais global, o autor avalia que as teorias da comunicação surgiram a partir de análises de fenômenos ligados à persuasão, à capacidade de influência da mídia sobre os ganhos na redução de incertezas, à integração social 
e à transmissão de informações. Os resultados das análises contribuíram muito mais para legitimar, reproduzir e manter o consenso do que para avançar na direção de um processo de tomada de decisão, construído mutuamente na interação entre os sujeitos envolvidos na ação comunicacional. Nesse sentido Deetz (1997) corrobora a ideia de que a filosofia do controle, imbricada nas concepções das ciências sociais e da comunicação e impressa nas sociedades democráticas, é um dos desafios a serem superados para que a participação, também nas organizações sociais, seja central e genuína no processo de tomada de decisões.

\section{REFERÊNCIAS}

BRAGA, José Luiz. Constituição do campo da comunicação. In: FAUSTO NETO, Antônio (Org.). Campo da comunicação: caracterização, problematizações, perspectivas. João Pessoa: Editora da UFPB, 2001.

DEETZ, Stanley. Communication in the age of negotiation. Journal of communication, n. 47, p. 118-135, 1997.

Transforming communication, transforming business: building responsive and responsible workplaces. Cresskill, NJ: Hampton Press, Inc., 1995.

FAUSTO NETO, Antônio. Fragmentos de uma 'analítica' da midiatização. Matrizes, São Paulo: ECA-USP, a. 1, n. 1, p. 89-105, 2007, Disponível em: <http://www.usp.br/matrizes/img/02/Dossie5 fau.pdf>. Acesso em: 16 fev. 2009.

JAMESON, F. Forward. In: LYOTARD, Jean-François. The postmodern condition: a report in knowledge. Manchester, UK: Manchester University Press, 1997. p vii-xxi.

KUNSCH, Margarida M. Krohling. Relações públicas e modernidade: novos paradigmas na comunicação organizacional. São Paulo: Summus, 1997

LYOTARD, Jean-François. The postmodern condition: a report in knowledge. Manchester, UK: Manchester University Press, 1997. MARTíN-BARBERO, Jesús. Dos meios às mediações: comunicação, cultura e hegemonia. Rio de Janeiro: Editora da UFRJ, 2001. PUTNAM, Linda L.; PHILLIPS, Nelson; CHAPMAN, Pamela. Metaphors of_communication and organization. In: CLEGG, Stewart; HARDY, Cynthia; NORD, Walter (Ed.). Handbook of organization studies. London / Thousand Oaks: Sage Publications, 1996. p. 375-408.

RAIMUNDO, Valéria de Fátima. Comunicação organizacional no trabalho mediado pelas novas mídias: estudo analítico das percepções de lideranças e teleatendentes em centrais de relacionamento. 2009. 242 fl. Tese (Doutorado em Sociologia) - Universidade Federal de Minas Gerais, Belo Horizonte, 2009.

REIS, Maria do Carmo; COSTA, Dulcemar J. A zona de interseção entre o campo da comunicação e os estudos organizacionais. In: FERREIRA, Jairo (Org.). Cenários, teorias e epistemologias da comunicação. Rio de Janeiro: E-Papers, 2007. p. 55-67.

SIMMEL, Georg. Questões fundamentais da sociologia: indivíduo e sociedade. Rio de Janeiro: Jorge Zahar, 2006.

SODRÉ, Moniz. Antropológica do espelho: uma teoria da_comunicação linear e em rede. Rio de Janeiro: Vozes, 2008.

THOMPSON, John B. A nova visibilidade. Matrizes, São Paulo: ECA-USP, a. 1 n. 2, p. 15-38, 2008.

YUNES, Maria Angela M.; SZYMANSKI, Heloísa. Entrevista reflexiva \& grounded-theory: estratégias metodológicas para compreensão da resiliência em famílias. Revista Interamericana de Psicología / Interamerican Journal of Psychology, 2005, v. 39, n. 3, p. 01-09, 2005.

Recebido em: 17.12.2009 / Aceito em: 02.02.2010 